Endovascular Treatment of Degenerative Aneurysms Involving

Only the Descending Thoracic Aorta : Systematic Review and Meta-analysis

\title{
Biancari, Fausto
}

2016-04

Biancari , F , Mariscalco , G , Mariani , S , Saari , P , Satta , J \& Juvonen , T 2016 , '

Endovascular Treatment of Degenerative Aneurysms Involving Only the Descending

Thoracic Aorta : Systematic Review and Meta-analysis ' , Journal of Endovascular Therapy , vol. 23 , no. 2 , pp. 387-392 . https://doi.org/10.1177/1526602815626560

http://hdl.handle.net/10138/161342

https://doi.org/10.1177/1526602815626560

publishedVersion

Downloaded from Helda, University of Helsinki institutional repository.

This is an electronic reprint of the original article.

This reprint may differ from the original in pagination and typographic detail.

Please cite the original version. 


\title{
Endovascular Treatment of Degenerative Aneurysms Involving Only the Descending Thoracic Aorta: Systematic Review and Meta-analysis
}

Journal of Endovascular Therapy 2016, Vol. 23(2) 387-392 (C) The Author(s) 2016 Reprints and permissions: sagepub.com/journalsPermissions.nav DOI: 10.1 |77/I5266028/5626560 www.jevt.org

@SAGE

\author{
Fausto Biancari, MD, PhD', Giovanni Mariscalco, MD, PhD², Silvia Mariani, MD², \\ Petri Saari, MD, PhD $^{3}$, Jari Satta, MD, PhD' $^{\prime}$, and Tatu Juvonen, $M D, P^{4} D^{4,5}$
}

\begin{abstract}
Purpose: To determine the efficacy of thoracic endovascular aortic repair (TEVAR) for degenerative aneurysm involving only the descending thoracic aorta (DTAA). Methods: An English-language literature review was performed through PubMed, Scopus, and Google Scholar to identify any study evaluating the outcomes of TEVAR for DTAA. The main endpoints of this analysis were all-cause 30-day and late postoperative mortality. Secondary outcome measures were procedure success, vascular access complications, paraplegia, stroke, early endoleaks during the index hospitalization, aneurysm-related death, reinterventions, and conversion to open repair. To control for the anticipated heterogeneity among small observational studies, absolute values and means were pooled using random effects models; the results are expressed as pooled proportions, means, or risk ratio (RR) with $95 \%$ confidence intervals $(\mathrm{Cls})$. Results: Eleven studies reporting on 673 patients (mean age 72.6 years, mean aneurysm diameter $62.9 \mathrm{~cm}$ ) with DTAA were selected for the analysis. Technical success was reported in $91.0 \%$ of patients, and vascular access complications requiring repair were encountered in $9.7 \%$ of cases. Pooled overall 30-day, I-year, 2-year, and 3-year survival rates were $96.0 \%, 80.3 \%, 77.3 \%$, and $74.0 \%$, respectively. Five studies compared the results of TEVAR after elective $(n=|5|)$ and urgent/emergent procedure $(n=77)$; the latter was a predictor of 30 -day mortality $(I 7.1 \%$ vs I.8\%, RR 3.83, 95\% Cl I.I8 to 12.40, $\mathrm{p}=0.025$ ). Paraplegia occurred in $3.2 \%$ of patients and was permanent in $1.4 \%$ of patients. The stroke rate was $2.7 \%$. Early type I endoleak was observed in $7.3 \%$, type II endoleak in $2.0 \%$, and type III in $1.2 \%$ of patients. The mean follow-up of 9 studies was 22.3 months. At 3 years, freedom from reintervention was $90.3 \%$. Death secondary to aneurysm rupture and/or fistula was reported in $3.2 \%$ of patients. Conclusion: Current results indicate that TEVAR for DTAA can be performed with rather high technical success, low postoperative morbidity, and good 3-year survival.
\end{abstract}

\section{Keywords}

aneurysm, descending aorta, mortality, paraplegia, reintervention, stent-graft, stroke, thoracic aortic aneurysm, thoracic endovascular aortic repair

\section{Introduction}

Because the rupture risk of untreated aneurysms of the descending thoracic aorta is so pronounced, ${ }^{1}$ a policy of repairing descending thoracic aortic aneurysms (DTAA) is advocated even in the very elderly. The introduction of endovascular technology allowed the treatment of aortic diseases with lower risk of early mortality and morbidity compared with open surgical repair. ${ }^{2}$ However, comparative analyses of these 2 treatment strategies were based on small series and were not adjusted for differences between the surgical and endovascular populations. ${ }^{3-9}$ Still, the results suggest that endovascular repair may provide better immediate outcome with midterm results that are not inferior to open surgery. ${ }^{3-9}$
A major limitation of current studies evaluating the safety and efficacy of thoracic endovascular aortic repair (TEVAR) is that only infrequently were they focused solely

\footnotetext{
'Department of Surgery, Oulu University Hospital, Oulu, Finland ${ }^{2}$ Department of Cardiovascular Sciences, University of Leicester, Glenfield Hospital, Leicester, UK

${ }^{3}$ Department of Clinical Radiology, Kuopio University Hospital, Kuopio, Finland

${ }^{4}$ Department of Surgery, University of Oulu, Finland

${ }^{5}$ Department of Cardiac Surgery, HUCH Heart and Lung Center, Helsinki University Central Hospital, Helsinki, Finland

Corresponding Author:

Fausto Biancari, Department of Surgery, Oulu University Hospital, P.O. Box 21, 90029 Oulu, Finland.

Email: faustobiancari@yahoo.it
} 
on atherosclerotic degenerative aneurysms involving the descending thoracic aorta. Furthermore, most of the studies also included patients with aneurysms involving the aortic arch and/or the abdominal aorta, whose treatment is expected to be more complex and risky. This void in the literature has clinical implications because DTAA most often affects the very elderly, whereas aortic dissection and blunt aortic trauma are more often observed in younger patients. ${ }^{10}$ The present study was planned to pool the immediate and late outcome data after TEVAR for DTAA alone in order to evaluate the efficacy and durability of endovascular treatment for degenerative aneurysms in this thoracic aortic segment.

\section{Methods}

\section{Search Strategy}

An English-language literature review was performed through PubMed, Scopus, and Google Scholar on July 15, 2015 , to identify any study evaluating the outcome of TEVAR for degenerative aneurysms involving the descending thoracic aorta. The search terms were "endovascular," "descending," "thoracic," "stent-graft," and "aneurysm." The guidelines for Preferred Reporting Items for Systematic reviews and Meta-Analyses (PRISMA) were applied. ${ }^{11}$ Three authors (F.B., S.M., G.M.) independently reviewed the abstracts and articles. Reference lists in the retrieved articles were searched.

\section{Treatment Definition and Inclusion/Exclusion Criteria}

For the purpose of this study, TEVAR was considered any stent-graft procedure for treatment of degenerative aneurysm involving only the DTA where the stent-graft was deployed in Ishimaru landing zones 2 to $4^{12}$ without covering the celiac axis. Patients who underwent carotid-subclavian bypass were eligible, but patients who underwent any other proximal debranching procedure were not. Similarly, patients with thoracoabdominal aortic aneurysm, acute or chronic aortic dissection, penetrating atherosclerotic ulcer, blunt trauma, or any distal debranching procedure were ineligible.

Each study was independently evaluated by all coauthors for inclusion or exclusion from this analysis. To enter this analysis, studies had to (1) provide detailed baseline, operative, and outcome data of patients who underwent TEVAR for DTAA, (2) be a prospective or retrospective observational investigation of $\geq 20$ adult patients, (3) be published in the English language as a full article after 1999, and (4) report on at least immediate postoperative mortality. The language of the articles was defined as reported in PubMed. Data from abstracts or unpublished material were not included.
Articles were ineligible for analysis if they (1) reported ambiguous or inaccurate data (discrepancies between the text and tables); (2) had no information on baseline characteristics, treatment modality, need and extent of debranching procedure, or data on the primary endpoint; (3) derived data from administrative databases; or (4) reported mixed data on TEVAR for aneurysms other than those solely in the DTA.

\section{Data Extraction}

Data were retrieved only from the articles, and no attempt was made to obtain specific or missing data from the authors. The following data were extracted: first author, year of publication, study period, study design, number of patients, gender, aneurysm size, major comorbidities, proximal and distal landing zones, debranching procedures, use of prophylactic cerebrospinal fluid (CSF) drainage, procedure success, number of stent-graft devices implanted, 30-day mortality, paraplegia, stroke, types of early endoleaks, length of follow-up, overall survival, aneurysmrelated deaths, reinterventions, and conversions to open repair.

\section{Outcome Measures}

The main endpoints of this analysis were all-cause 30-day and late postoperative mortality. Secondary outcome measures were procedure success, vascular access complications, paraplegia, stroke, endoleak during the index hospitalization, aneurysm-related death, reinterventions, and conversion to open repair. Definitions for these endpoints were those adopted by the investigators of the included studies. Aneurysm-related death included any mortality related directly to the aneurysm, such as rupture or fistula, ascertained at the time of treatment or at autopsy.

\section{Statistical Analysis}

To control for the anticipated heterogeneity among small observational studies, absolute values and means were pooled using random effects models; the results are expressed as pooled proportions or means with $95 \%$ confidence intervals (CIs). Analysis of time-to-event outcome endpoints was performed by calculating the number of patients at risk from available survival curves and tables using a spreadsheet developed by Tierney and collaborators. ${ }^{13}$ Heterogeneity across studies was evaluated using the $\mathrm{I}^{2}$ test. The quality of the included studies was assessed using the National Heart, Blood, and Lung Institute (NHBLI) criteria for study quality assessment of cases series (http:// www.nhlbi.nih.gov/health-pro/guidelines/in-develop/cardiovascular-risk-reduction/tools/). Sensitivity analysis and meta-regression were performed to evaluate the impact of 


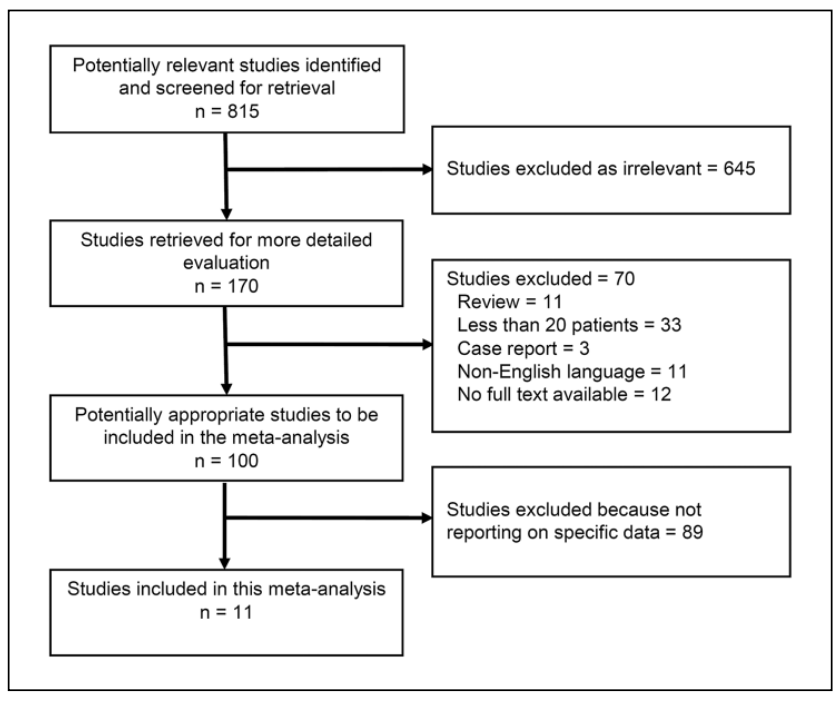

Figure I. Flowchart of the literature search.

covariates on the development of postoperative stroke. $\mathrm{p}<0.05$ was considered statistically significant. Statistical analysis was performed using the open access software Open Meta-Analyst (Brown University, Providence, RI, USA; http://www.cebm.brown.edu/openmeta/)

\section{Results}

Figure 1 summarizes the results of the literature search. Eleven studies reporting on 673 patients with DTAA were included in this meta-analysis. ${ }^{7,9,14-22}$ Characteristics of these studies are summarized in Table 1. Patients undergoing TEVAR had a mean age of 72.6 years, and their mean maximum aneurysm diameter was $62.9 \mathrm{~mm}$ (Table 2).
There was a high prevalence of coronary artery disease (46.8\%) and chronic obstructive pulmonary disease (38.4\%). The stent-graft was deployed into Ishimaru zone 2 in $14.1 \%$ of cases, and debranching procedures for revascularization of the left subclavian artery (LSA) were performed in $14.1 \%$ of patients. A mean 1.8 stent-grafts was deployed in procedures with a mean duration of $146 \mathrm{~min}$ utes. Eight of 11 studies were of good quality as assessed by the NHBLI criteria.

Table 3 summarizes the pooled immediate and late outcome after TEVAR. Technical success was reported in $91.0 \%$ of patients, and vascular access complications requiring repair were encountered in $9.7 \%$ of cases. Type I endoleak was observed early after TEVAR in $7.3 \%$, type II endoleak in $2.0 \%$, and type III in $1.2 \%$ of patients.

Pooled overall 30-day mortality was $4.0 \%$ (95\% CI 2.0 to $6.0, \mathrm{I}^{2}=42 \%$ ). Five studies compared the results of TEVAR after elective $(n=151)$ and urgent/emergent procedures $(\mathrm{n}=77)$; the latter was a predictive factor for 30-day mortality $[17.1 \%$ vs $1.8 \%$, risk ratio (RR) $3.83,95 \% \mathrm{CI}$ 1.18 to $12.40, \mathrm{p}=0.025]$. Nine studies provided data on at least 1-year survival based on a mean follow-up of 22.3 months. Pooled overall 1-, 2-, and 3-year survival rates were $80.3 \%, 77.3 \%$, and $74.0 \%$, respectively (Table 3 , Figure 2). Death secondary to aneurysm rupture and/or fistula was reported in $3.2 \%$ of patients.

Paraplegia occurred in $3.2 \%$ of patients and was permanent in $1.4 \%$. In $2(8.7 \%)$ of 23 cases, postoperative paraplegia was reversed by blood pressure management and CSF drainage. ${ }^{14,18}$ Data on CSF drainage were reported in only 5 studies; this neuroprotective method was employed in $30.6 \%$ of 305 patients.

Five studies evaluated the risk of stroke with and without coverage of the LSA. The stroke rate was $2.7 \%$. LSA

Table I. Characteristics of Studies Evaluating Outcomes After Endovascular Treatment for Degenerative Aneurysm of the Descending Thoracic Aorta.

\begin{tabular}{|c|c|c|c|c|c|c|c|c|}
\hline Author, Year, Country & Study Period & $\begin{array}{l}\text { Study } \\
\text { Design }\end{array}$ & $\begin{array}{l}\text { Study } \\
\text { Quality }^{\mathrm{a}}\end{array}$ & $\mathrm{N}$ & $\begin{array}{l}\text { Elective } \\
\text { Cases }^{b}\end{array}$ & Stent-Grafts & $\begin{array}{l}\text { Ishimaru Landing } \\
\text { Zone, } 2 / 3-4^{\mathrm{b}}\end{array}$ & $\begin{array}{l}\text { Debranching } \\
\text { Procedures }^{b}\end{array}$ \\
\hline Neuhauser, 2004, Austria & 1997-2003 & $\mathrm{R}$ & Fair & 31 & 58 & Mixed & $26 / 74$ & 3 \\
\hline Makaroun, 2005, USA & |999-200| & $P$ & Good & 139 & 100 & Gore TAG & $20 / 80$ & 20 \\
\hline Glade, 2005, Netherlands & 1999-2003 & $\mathrm{R}$ & Good & 42 & 83 & Mixed & $0 / 100$ & 0 \\
\hline Marcheix, 2006, France & $1996-2005$ & $P$ & Good & 45 & 82 & Mixed & $13 / 87$ & 0 \\
\hline Appoo, 2006, USA & 1999-2005 & $P$ & Good & 99 & - & Mixed & $20 / 80$ & 20 \\
\hline Cambria, 2009, USA & $2005-2007$ & $P$ & Good & 20 & 0 & Gore TAG & $0 / 100$ & 0 \\
\hline Hughes, 2010, USA & $2005-2009$ & $\mathrm{R}$ & Fair & 79 & 30 & Mixed & $42 / 58$ & 5 \\
\hline Desai, 2012, USA & $1995-2007$ & $\mathrm{P}$ & Good & 106 & 92 & Mixed & $20 / 81$ & 17 \\
\hline Yunoki, 20I4, Japan & $2008-2011$ & $\mathrm{R}$ & Good & 36 & 100 & Gore TAG & $0 / 100$ & 0 \\
\hline Saratzis, 2007, Greece & $2003-2005$ & $\mathrm{R}$ & Fair & 23 & 100 & EndoFit & $0 / 23$ & 0 \\
\hline Saari, 20I3, Finland & $1998-2010$ & $\mathrm{R}$ & Good & 53 & 77 & Mixed & $9 / 44$ & 8 \\
\hline
\end{tabular}

Abbreviations: $\mathrm{P}$, prospective; $\mathrm{R}$, retrospective.

${ }^{a}$ Quality of these studies was assessed by the National Heart, Blood, and Lung Institute criteria for quality assessment of case series.

bData are given as the percentages. 
Table 2. Pooled Baseline and Operative Characteristics of 673 Patients Who Underwent Endovascular Treatment for Degenerative Aneurysm of the Descending Thoracic Aorta.

\begin{tabular}{|c|c|c|c|c|c|}
\hline Variables & Pooled Proportion, $\%^{\mathrm{a}}$ & $\operatorname{Mean}^{\mathrm{a}}$ & Studies, $\mathrm{n}$ & Patients, $\mathrm{n}$ & $I^{2}, \%$ \\
\hline Age, y & & 72.6 (7I.3 to 73.9$)$ & 9 & 608 & 59 \\
\hline Women & 29.9 (I5.8 to 43.9$)$ & & 8 & 566 & 94 \\
\hline CAD & 46.8 (34.4 to 59.1$)$ & & 10 & 631 & 91 \\
\hline CVD & 10.7 (7.8 to I3.6) & & 7 & 441 & 0 \\
\hline COPD & 38.4 (27.9 to 48.9$)$ & & II & 673 & 89 \\
\hline Aneurysm diameter, $\mathrm{mm}$ & & $62.9(60.4$ to 65.3$)$ & 9 & 547 & 69 \\
\hline Prior aortic procedure & 22.2 ( 1.0 to 34.7$)$ & & 6 & 321 & 90 \\
\hline Elective procedure & $72.4(55.1$ to 89.6$)$ & & 10 & 574 & 99 \\
\hline Ishimaru landing zones & & & $\mathrm{II}$ & 673 & \\
\hline 2 & I4.I (7.6 to 20.7) & & - & - & 91 \\
\hline $3 / 4$ & 86.0 (79.5 to 92.6$)$ & & - & - & 91 \\
\hline LSA coverage & I4.I (7.6 to 20.7$)$ & & 11 & 673 & 91 \\
\hline Debranching procedure & 7.3 (3.4 to II.3) & & $\mathrm{II}$ & 673 & 85 \\
\hline CSF drainage & $30.6(8.1$ to 53.0$)$ & & 5 & 305 & 97 \\
\hline Procedure duration, min & & $146(1||$ to $|8|)$ & 5 & 290 & 95 \\
\hline No. of devices implanted & & 1.8 (I.6 to 2.1$)$ & II & 673 & 97 \\
\hline
\end{tabular}

Abbreviations: CAD, coronary artery disease; COPD, chronic obstructive pulmonary disease; CSF, cerebrospinal fluid; CVD, cerebrovascular disease; LSA, left subclavian artery.

${ }^{\mathrm{a}}$ Data are given with the $95 \%$ confidence interval in parentheses.

Table 3. Outcomes After Endovascular Treatment for Degenerative Aneurysm of the Descending Thoracic Aorta.

\begin{tabular}{|c|c|c|c|c|c|}
\hline Outcome Measure & Pooled Proportion, \% ${ }^{\mathrm{a}}$ & $\operatorname{Mean}^{\mathrm{a}}$ & Studies, $\mathrm{n}$ & Patients, $\mathrm{n}^{\mathrm{b}}$ & $I^{2}, \%$ \\
\hline Mortality at 30 days & $4.0(2.0$ to 6.0$)$ & & II & 673 & 42 \\
\hline Technical success & $91.0(86.1$ to 95.9$)$ & & 10 & 426 & 91 \\
\hline Access complications requiring repair & $9.7(4.1$ to I5.2) & & 8 & 435 & 80 \\
\hline Paraplegia & $3.2(1.9$ to 4.5$)$ & & II & 673 & 0 \\
\hline Permanent paresis & I.4 (0.6 to 2.3$)$ & & $\mathrm{II}$ & 673 & 0 \\
\hline Stroke & $2.7(1.5$ to 3.9$)$ & & II & 673 & 0 \\
\hline \multicolumn{6}{|l|}{ Early endoleaks } \\
\hline Type I & 7.3 (3.5 to II.I) & & 10 & 567 & 78 \\
\hline Type II & $2.0(0.8$ to 3.2$)$ & & 10 & 567 & 5 \\
\hline Type III & $1.2(0.2$ to 2.3$)$ & & 10 & 567 & 23 \\
\hline Early or late reintervention & $9.6(6.5$ to 12.7$)$ & & $\mathrm{II}$ & 673 & 45 \\
\hline Early or late surgical reoperation & $1.4(0.5$ to 2.2$)$ & & 10 & 653 & 0 \\
\hline Aneurysm rupture/fistula-related death & $3.2(1.2$ to 5.2$)$ & & 9 & 525 & 42 \\
\hline Length of follow-up, mo & & $22.3(17.7$ to 27.0$)$ & 9 & 468 & 89 \\
\hline \multicolumn{6}{|l|}{ Survival } \\
\hline I-year & $80.3(72.2$ to 88.4$)$ & & 9 & 545 & 88 \\
\hline 2-year & 77.3 (69.4 to 85.4$)$ & & 8 & 457 & 76 \\
\hline 3-year & $74.0(65.3$ to 82.7$)$ & & 6 & 277 & 62 \\
\hline \multicolumn{6}{|l|}{ Freedom from reintervention } \\
\hline I-year & 93.4 (89.3 to 97.5$)$ & & 5 & 279 & 50 \\
\hline 2-year & $91.8(87.6$ to 96.1$)$ & & 5 & 224 & 28 \\
\hline 3-year & $90.3(85.3$ to 95.4$)$ & & 5 & 153 & 15 \\
\hline
\end{tabular}

a Data are given with the $95 \%$ confidence interval in parentheses.

${ }^{\mathrm{b}}$ The number of patients at risk at each follow-up interval was estimated using the method of Tierney et al. ${ }^{13}$

coverage was associated with a trend toward increased risk of stroke (pooled rates: $4.8 \%$ vs $3.1 \%$, RR $2.26,95 \%$ CI 0.40 to $12.46, \mathrm{p}=0.350$ ). The risk of stroke was not increased either by the proportion of coverage of the LSA $(\mathrm{p}=0.517)$ or the proportion of debranching procedures $(\mathrm{p}=0.317)$. 


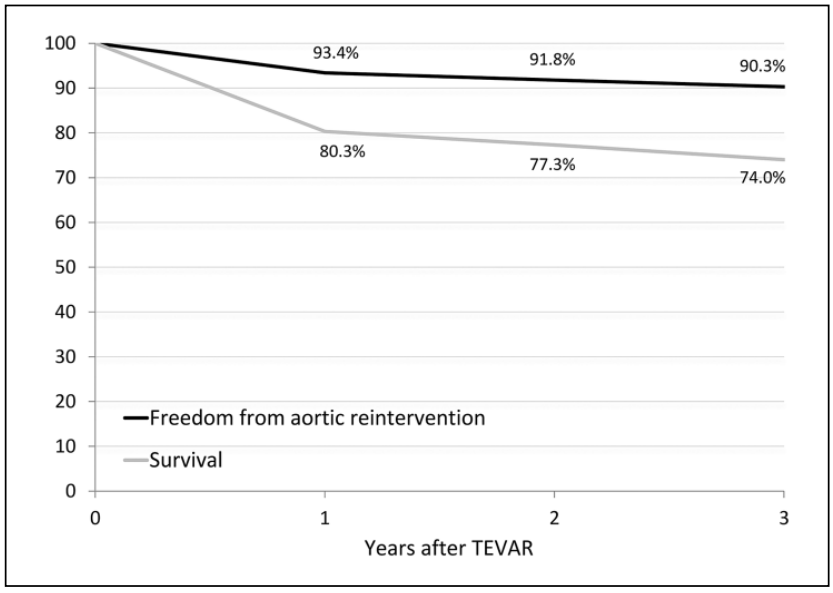

Figure 2. Pooled survival and freedom from aortic reintervention after endovascular treatment for degenerative aneurysm involving only the descending aorta.

Reintervention for complications after TEVAR was required in $9.6 \%$ of patients, with a freedom from reoperation of $90.3 \%$ at 3 years (Table 3, Figure 2). Open surgical reoperation was needed in $1.4 \%$ of patients.

\section{Discussion}

DTAA is a life-threatening condition in which the yearly rupture risk of aneurysms $>6 \mathrm{~cm}$ can exceed $10 \%$ in the elderly, particularly in the presence of pulmonary disease and chest pain. ${ }^{1}$ Elefteriades ${ }^{23}$ estimated that the yearly risk of rupture, dissection, or death of patients with any thoracic aneurysm $>6 \mathrm{~cm}$ is about $14 \%$. Although open surgery can be considered the standard procedure with a low risk of late complications, it is a major procedure associated with significant risk of mortality and morbidity. ${ }^{2}$ TEVAR seems to be associated with excellent early results compared with open surgery despite a somewhat higher risk profile of patients undergoing endovascular procedures. These results, as well as its less invasive nature, are reasonable arguments in favor of TEVAR, particularly in the treatment of DTAAs in the elderly. Any less invasive procedure carrying a lower risk of morbidity should be preferred in fragile, elderly patients. Indeed, an interventional policy that does not consider the high risk of postoperative morbidity associated with major cardiovascular surgery in the elderly can still achieve satisfactory postoperative survival, but with high social costs and poor quality of life in a number of survivors. ${ }^{24}$

The present pooled analysis indicates that TEVAR is a valid treatment in elderly patients with degenerative atherosclerotic aneurysm involving only the descending thoracic aorta. The study population was rather old and with high prevalence of coronary artery and pulmonary diseases. Importantly, one third of these patients underwent urgent/emergency procedures, which was associated with a significantly increased risk of mortality. However, elective TEVAR was associated with a $<2 \%$ 30-day mortality, which can be considered excellent. Although 3-year pooled survival was $74 \%$, it is worth noting that about $20 \%$ of patients had died by the 1-year follow-up. This figure can be partly explained by the high mortality in patients undergoing urgent/emergency operation. Furthermore, suboptimal intermediate survival was due to the poor health status suggested by the high prevalence of comorbidities.

The incidence of paraplegia was low, particularly when one considers that CSF drainage was used in a limited number of patients. It is likely that prophylactic neuroprotective strategies should be considered more frequently, particularly in patients undergoing coverage of the LSA and/or of the lowest third of the descending thoracic aorta, as well as in the setting of previous abdominal aortic aneurysm repair. ${ }^{16-18}$

TEVAR was performed in this series with a pooled technical success of $91 \%$ and a $7 \%$ incidence of early type I endoleak, which likely may be even lower with the use of newer devices. ${ }^{18}$ This translated into a $90 \%$ freedom from aortic reintervention at 3 years. The low proportion of patients with early and late aneurysm rupture/fistula-related mortality could be underestimated owing to the lack of autopsy data in all deceased patients.

About $10 \%$ of the population had vascular access complications requiring surgical or endovascular repair. Such complications are likely to decrease in the future with the increasing experience and technological development of TEVAR devices. However, all efforts should be made to avoid major vascular complications as the experience with transcatheter aortic valve replacement has shown that these sequelae can be associated with a significantly increased risk of mortality and morbidity, as well as incremental costs. ${ }^{25,26}$

\section{Limitations}

The major pitfall of the included studies was the rather short follow-up. In a few studies, the potential follow-up could have been almost 10 years, ${ }^{9}$ but still the authors did not provide data with enough long-term follow-up. This is a critical issue as these elderly patients, despite their comorbidities, may still have a rather long life expectancy as suggested by the 3-year pooled survival in this analysis. Longevity may favor the evolution of aneurysm disease as well as stent-graft fatigue. Six studies were retrospective and most of the studies failed to provide details on their methods of follow-up. The latter is a major shortcoming in the assessment of these high-risk patients as it may easily lead to overestimation of the survival outcome.

Autopsy was not performed in all patients who died suddenly, which may result in an underestimation of aneurysmrelated events. In fact, a recent multicenter study performed in Finland, ${ }^{22}$ where the autopsy rate is rather high and follow-up data are easy to collect, showed poorer 3-year survival (57\%) and freedom from aneurysm-related death (89\%).

Seven of 11 series included patients treated during the 1990s, which means that current results could be even 
better than represented in these pooled data as a result of significant improvements in stent-graft technology along with accumulated experience in major endovascular procedures. $^{18}$

\section{Conclusion}

There are limited data on the long-term outcome after TEVAR, which prevents conclusive opinions on the durability of this treatment. However, the available data showed that TEVAR for DTAA is safe and associated with rather low early mortality and morbidity risk. Pooled 3 -year survival of these patients appeared to be satisfactory.

\section{Declaration of Conflicting Interests}

The author(s) declared no potential conflicts of interest with respect to the research, authorship, and/or publication of this article.

\section{Funding}

The author(s) received no financial support for the research, authorship, and/or publication of this article.

\section{References}

1. Juvonen T, Ergin MA, Galla JD, et al. Prospective study of the natural history of thoracic aortic aneurysms. Ann Thorac Surg. 1997;63:1533-1545.

2. Walsh SR, Tang TY, Sadat U, et al. Endovascular stenting versus open surgery for thoracic aortic disease: systematic review and meta-analysis of perioperative results. $J$ Vasc Surg. 2008;47:1094-1098.

3. Andrassy J, Weidenhagen R, Meimarakis G, et al. Endovascular versus open treatment of degenerative aneurysms of the descending thoracic aorta: a single center experience. Vascular. 2011;19:8-14.

4. Patel HJ, Williams DM, Upchurch GR Jr, et al. A comparison of open and endovascular descending thoracic aortic repair in patients older than 75 years of age. Ann Thorac Surg. 2008;85:1597-1603.

5. Narayan P, Wong A, Davies I, et al. Thoracic endovascular repair versus open surgical repair - which is the more costeffective intervention for descending thoracic aortic pathologies? Eur J Cardiothorac Surg. 2011;40:869-874.

6. Dick F, Hinder D, Immer FF, et al. Outcome and quality of life after surgical and endovascular treatment of descending aortic lesions. Ann Thorac Surg. 2008;85:1605-1613.

7. Glade GJ, Vahl AC, Wisselink W, et al. Mid-term survival and costs of treatment of patients with descending thoracic aortic aneurysms. Endovascular vs. open repair: a case-control study. Eur J Vasc Endovasc Surg. 2005;29:28-34.

8. Makaroun MS, DillavouED, Wheatley GH, et al. Five-year results of endovascular treatment with the Gore TAG device compared with open repair of thoracic aortic aneurysms. J Vasc Surg. 2008;47:912-918.

9. Desai ND, Burtch K, Moser W, et al. Long-term comparison of thoracic endovascular aortic repair (TEVAR) to open surgery for the treatment of thoracic aortic aneurysms. $J$ Thorac Cardiovasc Surg. 2012;144:604-609.

10. Leurs LJ, Bell R, Degrieck Y, et al. Endovascular treatment of thoracic aortic diseases: combined experience from the EUROSTAR and United Kingdom Thoracic Endograft registries. J Vasc Surg. 2004;40:670-679.

11. Moher D, Liberati A, Tetzlaff J, et al. Preferred reporting items for systematic reviews and meta-analyses: the PRISMA statement. BMJ. 2009;339:b2535.

12. Ishimaru S. Endografting of the aortic arch. J Endovasc Ther. 2004;11(Suppl 2):II62-71.

13. Tierney JF, Stewart LA, Ghersi D, et al. Practical methods for incorporating summary time-to-event data into meta-analysis. Trials. 2007;8:16.

14. Yunoki J, Kuratani T, Shirakawa Y, et al. Mid-term results of endovascular treatment with the Gore TAG device for degenerative descending thoracic aortic aneurysms. Gen Thorac Cardiovasc Surg. 2015;63:38-42.

15. Marcheix B, Dambrin C, Bolduc JP, et al. Midterm results of endovascular treatment of atherosclerotic aneurysms of the descending thoracic aorta. J Thorac Cardiovasc Surg. 2006;132:1030-1036.

16. Makaroun MS, Dillavou ED, Kee ST, et al. Endovascular treatment of thoracic aortic aneurysms: results of the phase II multicenter trial of the GORE TAG thoracic endoprosthesis. J Vasc Surg. 2005;41:1-9.

17. Neuhauser B, Perkmann R, Greiner A, et al. Mid-term results after endovascular repair of the atherosclerotic descending thoracic aortic aneurysm. Eur J Vasc Endovasc Surg. 2004;28:146-153.

18. Appoo JJ, Moser WG, Fairman RM, et al. Thoracic aortic stent grafting: improving results with newer generation investigational devices. J Thorac Cardiovasc Surg. 2006;131:1087-1094.

19. Cambria RP, Crawford RS, Cho JS, et al. A multicenter clinical trial of endovascular stent graft repair of acute catastrophes of the descending thoracic aorta. J Vasc Surg. 2009;50:1255-1264.

20. Hughes GC, Lee SM, Daneshmand MA, et al. Endovascular repair of descending thoracic aneurysms: results with "onlabel" application in the post Food and Drug Administration approval era. Ann Thorac Surg. 2010;90:83-89.

21. Saratzis N, Saratzis A, Melas N, et al. Endovascular treatment of descending thoracic aortic aneurysms with the EndoFit stent-graft. Cardiovasc Intervent Radiol. 2007;30:177-181.

22. Saari P, Biancari F, Ihlberg L, et al. Early and midterm outcomes after endovascular treatment of degenerative aneurysms of the descending thoracic aorta: a Finnish multicenter study. J Endovasc Ther. 2013;20:257-264.

23. Elefteriades JA. Natural history of thoracic aortic aneurysms: indications for surgery, and surgical versus nonsurgical risks. Ann Thorac Surg. 2002;74:S1877-1880.

24. McKneally MF. "We didn't expect dementia and diapers": reflections on the Nihon experience with type A aortic dissection in octogenarians. J Thorac Cardiovasc Surg. 2008;135:984-985.

25. Généreux P, Webb JG, Svensson LG, et al. Vascular complications after transcatheter aortic valve replacement: insights from the PARTNER (Placement of AoRTic TraNscathetER Valve) trial. J Am Coll Cardiol. 2012;60:1043-1052.

26. Mwipatayi BP, Picardo A, Masilonyane-Jones TV, et al. Incidence and prognosis of vascular complications after transcatheter aortic valve implantation. J Vasc Surg. 2013;58:1028-1036. 